Environmental Values 7 (1998): 349-57

\title{
Saving Nature, Feeding People, and the Foundations of Ethics
}

\author{
HOLMES ROLSTON, III
}

Department of Philosophy

Colorado State University

Fort Collins, CO 80203, USA

I welcome my thoughtful critics. If there is to be progress in environmental ethics, it will result from interchanges such as these. I start with my recent experience in Nepal, using that to bring to initial focus where I think my differences with Attfield, Brennan, and Minteer lie. Later I turn, in too summary a way, to some more specific complaints.

Royal Chitwan National Park in Nepal is a primary sanctuary for Bengal tigers and the Asian rhinoceros, both extremely endangered species. Other endangered species protected in the area are the sloth bear, the pygmy hog, the swamp dear, the black buck, the Asian rock python, and the gharial crocodile (the world's most endangered crocodile). The park exists because the region, in lowland Nepal, was too malarious to live in year round until the 1950's. In earlier years, what is now the park area was kept as a hunting preserve for the Rana rulers of Nepal in the dry season. Oddly, the tigers and rhinos survived because of the mosquitoes.

Following a mosquito eradication campaign in mid-century, Nepalis began to move into the region. The migrants cleared the forests and started cultivating crops, also poaching animals. In 1973, to increase protection, the hunting preserve was designated a national park. Nepalis were surrounding it. The population of the Terai (lowland) region was 36,000 in 1950; in less than a decade it was one million. With one of the highest birthrates in the world, and with the influx continuing, the population in 1991 was 8.6 million, 90 percent of them poor, 50 percent of them desperately poor (Nepal and Weber 1993; Shrestha 1997).

No one is allowed to live in the park. People complain that they cannot cut grasses, graze cattle and buffalo, or timber the park at will. They are allowed to cut thatch grasses several days a year, and 30 percent of park income is given to Village Development Committees. The Royal Nepalese Army is responsible for preventing poaching, grazing, cutting grasses, pilfering timber, and permanent habitation of the land. They also do what they can to improve the lot of the people. But being hungry is not a sufficient reason to sacrifice the park. That problem must be fixed by attacking its root social causes, even though, alas, in my visit to Nepal during January and February of this year, I did not find any answers in sight.

Environmental Values 7 (1998): 349-57

(C) 1998 The White Horse Press, Cambridge, UK. 


\section{HOLMES ROLSTON, III}

The Smithsonian Institution and the World Wide Fond for Nature conducted a Tiger Ecology Project there from 1973 to 1981, using Nepali and American researchers. No doubt they were concerned about the pressures of the poor on tiger habitat. No doubt also they spent money on preserving the tigers that might have been spent relieving poverty. One of their principal recommendations was to increase the size of the protected habitat.

I am arguing (contra Attfield) that such conservation dilemmas are very much with us in developing countries, are likely to remain so for some time to come, and that such conservation efforts can be morally justified. I argue (contra Brennan) that, complex though the social factors that produce poverty may be, there is no particular cause here to fault transnational corporations or development agencies. About one-half of the government's revenue depends on foreign aid and borrowing; one-third of the hard currency entering the country is aid. Nor do I fault as 'brutal and ruthless' the Nepali military forces that police the park, even though military powers can sometimes be so, as Brennan worries (p. 330). Maybe those who eradicated the mosquitoes caused all the trouble; maybe they and their international aid-granting supporters were attacking Nepal's poverty in the wrong way. Meanwhile, today we ('we' who decide how to help in Nepal) have a tough decision.

I put the tigers first, have financially supported WWF efforts to save Asian and African species, and morally approve the present policies, on grounds that tigers as a species ought not to be sacrificed on the altar of human mistakes, regardless of what persons made mistakes where in the complex chains of events. Moved by the lack of medical care in the region, I also sent, upon my return, a $\$ 5,000$ contribution to one of the very few hospitals nearby, which I visited.

If I did not believe (contra Minteer) that tigers have intrinsic value, if I did not believe that species lines are morally considerable, if I thought the values of tigers were only those that this or that culture chooses to assign to them, or not, I would not be making such efforts to protect them. I puzzle to know what arguments (or forces), if any, Minteer would use encountering the Nepalis who wish to sacrifice the park to relieve their poverty. Since I am so insensitive to the loggers in the Pacific Northwest, he will think worse of my defense of the tigers over the poor of Nepal. But why should I accept his views? They are without 'foundations'; they only come from whatever 'culturally-occupied' subculture he belongs to.

Next, I turn to a selected few of my critics' more specific complaints.

Faced with a dilemma, we first try to find a way out by showing that it is not the dilemma supposed. No hard choices need to be made. We can have our cake and eat it too. That is essentially the strategy taken by Attfield. If there were an ideal development process, Nepal could have its millions in the Terai and its tiger sanctuary as well. Africa could have its present human populations, which are typically three times what they were at mid-century, and the rhinos restored, which have declined to 2,500 in a quarter century from a population of 60,000, a decline of 96 percent (Cunningham and Berger 1997). 


\section{SAVING NATURE ...}

Of if not so many people, rhinos, or tigers, compromising these numbers, there is some way to solve the problem by which people need not get hurt. There is no dilemma. Or at least 'such conflicts would be rare' (Attfield, p. 296). That is not, however, what the World Health Organization has found: 'Priority given to human health raises an ethical dilemma if "health for all" conflicts with protecting the environment. ... Priority to ensuring human survival is taken as a first-order principle. Respect for nature and control of environmental degradation is a second-order principle, which must be observed unless it conflicts with the first-order principle of meeting survival needs' (WHO Commission on Health and Environment 1992:4). That is quite humane; it also means no tigers or rhinos.

Has Attfield forgotten that I began by saying: 'One ought to seek win-win solutions whenever one can' (1996:249)? I conceded that some strategies that are morally desirable are not politically possible. My analysis is not of some ideal world, but of the real world where win-lose decisions face us daily. As much as anyone else, I will convert such a situation into win-win if I can. Only I face the reality that they do not so easily or so soon convert. 'Population policies (if voluntary, and integrated with policies of development) have the potential for eventually limiting the incidence of conflicts between preservation and human needs' (Attfield, p. 296). Eventually, but the incidence of conflicts has been escalating for the last half century, and shows little sign of slacking off, especially conflicts threatening the charismatic megafauna.

It is well enough to conclude that 'the kind of policies needed in the Third World are ones which enlist people's energies for producing food and preserving nature alike' (Attfield, abstract). No dilemma - if and when we get those needed policies. Meanwhile, there is a dilemma now at Royal Chitwan, and if we wait for those kinds of policies to work, the tigers and rhinos will be gone. ${ }^{1}$ The fact of the matter is that what sustainably gets humans fed in Nepal can and probably will sacrifice a great deal of biodiversity. Nature co-opted to feed people is seldom wild nature saved.

With Attfield's complaints about my calling the tenth-child, tenth-child multiplication factor a tragedy, I stand by my claims. These numbers are admittedly provocative tropes for the real world, where often a women does produce five children, on average (as has been true in rural Nepal). Likewise the term 'cancer' is deliberately provocative, a shocking term, but there are analogies enough to make it sting, as it did both Attfield and Brennan. "Uncontrolled growth' (sometimes named 'cancer' and sometimes 'population explosion') is growth gone beserk, pathological, self-defeating, eventually tragic. Even with humans there is a good-better-best fallacy. One human is good; more are better. And the most is the best?

Attfield doesn't believe that; he has only three children. Humans too are subject to the constraints of exponential growth. Where there are too many children, make the best of a bad situation. But do not suppose that it is not a bad situation, and learn from it for the next generation. Attfield concedes: 'This could 


\section{HOLMES ROLSTON, III}

still be a tragedy, all things considered' (p. 299). The reason for the tragedy is uncontrolled growth (aka 'cancer'). The uncontrolled growth is not always in head count. It can also be in desires for profits, for capital, or the size of one's fishing fleet on Lake Victoria, as Brennan notes. It can also be in unnecessary consumption.

Wherever the unregulated human growth, do not suppose that, in such a bad situation, one should always solve the problem by sacrificing endangered species and their habitat. There are better ways to be humane, as humane as one can, but stopping short of extinguishing species, else we lose the species only to continue the human tragedy. That brings agonising decisions; it brings Brennan' s wrath as 'astonishing misanthropy' (p. 326). On this spectacular planet, with many millions of species, maybe it is astonishing anthropocentrism to hold that people always come first, no matter what their mistakes, no matter where their uncontrolled growth.

Attfield twists and turns to escape the dilemma, by hoping that poor parents might find ways to care for increasing numbers of children with their limited resources (the tenth child cooks at the same fire as the first child) (p. 298). But he cannot always escape the dilemma, as he himself recognises. He and I mostly differ in that I think, in the real world of inflating populations, these dilemmas will be common; he thinks, in his more ideal world, they will be rare. I am accused of the Malthusian delusion; in reply, I cite the Nepali Terai as evidence that there is truth enough there to produce moral agony.

'Development', Attfield wants to stipulate, should only mean 'change which is genuinely for the better, and not just change believed by someone to be such' (p. 293). In that case, "bad development' is an oxymoron, and 'sustainable development' is a tautology. Meanwhile, we do need some term for what has been taking place in Nepal, India, Africa, East Asia and South America over the last half century, indeed some term for what has been happening in North America and Europe since the Enlightenment, where many changes, brought about by people called 'developers' of one kind or another, have brought a mixture of good and bad results.

Depending on one's view of sustainability, there can be much sustainable development that sacrifices endangered species and their habitats, which seldom need to be kept preserved for these species in order to keep people healthy. Typically agriculture introduced to previously wild areas, normally called a development, does destroy wildlife habitat. 'Development which is unsustainable ... will undermine itself', Attfield assures us (p. 293). Yes, but by the time it does, the tigers in Nepal, the rhinos there and in Africa, and the lemurs in Madagascar, will be extinct. One of my main points is that the 'feeding people' gained by 'sacrificing nature' is, in most cases, only a temporary solution to a problem that needs to be solved at its roots in the birthrate patterns or social inequities that result in hunger. Else, one will find, a decade later, that the people are hungry again, because the problem was not attacked in the right place. 
Brennan is anxious to get the problems attacked in the right places. That is what upsets him about my use of 'we'. I 'adopt "them" and "us" strategies' (p. 324). 'Elitist Puritan' that I am, I cannot see the connections between their poverty and our responsibility. My analysis 'overlooks relevant layers of agency and omits significant historical data' (p. 329). My 'we' is speaking from the First World; it editorially collects those of us who are involved in deciding where to place our efforts and our aid. 'They' are, collectively, those in need of such help. Brennan laments that my account, dichotomised so into 'we' and 'they', is impoverished by 'the absence of any discussion of the politics of international, relations, the ethics of holarchies and the forces which simultaneously drive human impoverishment, disease and environmental destruction." Pending a 'detailed analysis' of all these factors, which might find us as implicated as them, we ought not to advocate 'sealing off the last remaining wild places while hungry people die at the fences' (p. 324).

I am much faulted for my 'silence' about these complexities, these other actors lurking further back who are more responsible than the up front poor. Well, I could only do so much in one article. Brennan' s paper is much longer than mine that he critiques, and he concludes with an apology that his own analysis lacks detail. I warned, in the third paragraph, about 'abstracting from the complex circumstances of decision' (1998:248-249). I thought I had said clearly enough that the problem had to be fixed where it arose, in social structures, and could not really be fixed by sacrificing wild nature (1998:255). I diagrammed my disapproval of the five-to-one inequitable distribution of resources, North versus South, G-7 versus G-77, rich versus poor (1998:256). I censured military spending (1998:251 -252). I noted that exploiters are amply ready to exploit both people and nature, both in the U.S, where people go hungry, and abroad. How is this a simplistic 'individualist stance'? (Brennan, p. 324).

I nowhere said that 'we' are guiltless. I did say that 'we' Americans (and everybody else) sometimes correctly give priority to other values besides feeding the poor, as Brennan likewise does, when he educates his children, or flies regularly from Australia to Norway and Belgium to serve as a visiting professor. One minute Brennan is complaining that I know no guilt in my American culture; the next he is calling me a reversed Puritan Romantic (whatever that means) because 1 see so much sin in society and none in nature. I thought I complained about escalating consumerism. I advocated 'taxing the wealthy to feed the poor', 'using the produce of the already domesticated landscape justly and charitably' (1998:255).

Brennan and I differ, as nearly as I can make out, in that, until he can analyse and fix the Nepali problem by remedying these complicated networks at many levels, he will let people into Chitwan National Park, on grounds that sealing them out is not morally defensible. Of course, long before he gets the problem fixed, there will be no tigers in his morally improved world, as there will be none in Attfield's world. He doesn't want to be a Puritan, and there he may succeed. 


\section{HOLMES ROLSTON, III}

But the people in his tigerless world may still be hungry. Waiting for his program to work he has decided against the tigers by default.

Turning to Minteer, whose concern - on first appearances at least - is radically different, consider the foundations of these ethics that Attfield, Brennan, and I have been debating. I, for one, do not mind having an environmental ethics with some 'foundations.' Does Minteer want one without foundations? Yes, he urges us, in conclusion, to 'become comfortable with the contingency of our values' (p. 346). But then again, no, he wants his foundations to be in culture, not in nature. He wants environmental ethics to be 'more culturally-occupied' (p. 335). His ethics 'places human cultural experience into the foreground' (p. 335, p. 344). I want, he thinks, to 'retreat from culture.' 'Retreat', like foundationalist', (and like Brennan's 'Romantic Puritanism', fleeing evil culture) is being used pejoratively. If I were choosing the words, I would say that I want to 'go beyond' culture, or be more 'inclusive' than building an ethic only on contingent human preferences.

I do not want to be too purely 'culturally-occupied.' I am not sure (contra Minteer) that I need 'the purest . . . foundationalism' either (p. 337). But I do want to know enough about the natural world, independently of human cultures, to form some judgments about whether there are intrinsic values present which, when I encounter them, I ought appropriately to respect. I find that this respect for nonhuman values does at times shape my behaviour when dealing with the natural world. Most of our decisions are made, I concede, with culture in the foreground; but some should be made bringing into focus this 'background' that is, after all, our life-support system, and not only ours but that of many millions of other species. Now we can see that Minteer's concerns about whether to put society or nature up front do connect with Attfield's and Brennan's concerns that I sometimes prioritise nature over culture.

Should our environmental ethics be more 'culturally-occupied' (aka culturally constructed)? Ought it to be built up when various parties, choosing their values in nature, meet together democratically and put their puzzle pieces together? Elsewhere, I have addressed the question of the social construction of nature, an analysis that Minteer seems not to know. Readers who wish to explore this issue in more depth may wish to consult my argument, which is, briefly, that 'we cannot correctly value what we do not to some degree correctly know' (Rolston, 1997:40). 'Nature,' 'environment', 'wilderness', 'science', 'Earth', and 'value' so we are being told by post-modernists - are social constructs, by some accounts nothing but social constructs. Our language so colours up what we see that we do not really see what is there at all. We frame up whatever is out there in some 'context,' constituting it out of our interactive experience. I do want to retreat from this avant garde in cultural studies.

I seek indeed to put humans 'in context', not only with other humans, but as members with myriads of other species in a biotic community of life on Earth. I am resisting putting everything else on Earth in 'our context', on the flimsy 
grounds that we really cannot know anything in any other way. Within cultures, analogously, 1 do not seek to deal with Africans only in my American context on grounds that 1 cannot know their alien culture in any other way. Our human 'context' is both ecological and social, both natural and cultural. We have considerable powers, enhanced in both science and ethics, to see more disinterestedly.

We are able, to some degree, to separate out culture from wild nature, as we do when we designate a wilderness, and set it aside as a place where humans only visit and do not remain, where the works of humans are substantially unnoticeable. I do not need 'immutable first principles which enjoy a universal currency' (p. 334) (high class language, used with a pejorative twist). But I do need nature there in, with, and under culture, nature as the environment of culture. I need that much foundation. I do not need 'Truth' (p. 337) (again with a high sounding, pejorative capital T). I do need in some degree correctly to know something objective (what is the case apart from my subjective 'horizon of significance' [p. 341]) about the fauna and flora that Minteer is so ready to evaluate without any sure knowledge of these things at all. Far from impoverishing the values we seek to optimise in ethical decisions, I would like to 'thicken and deepen' this ethic (Minteer, p. 344) to count nonhumans morally, in ways in which Minteer, with his limited socially constrained epistemic capacities, will be incompetent to do. He can only be pragmatic about it,

I puzzle over Minteer's complaint that my ethic is somehow not 'experiencebased', not 'historical'. In my Environmental Ethics (1987), the opening chapter lists a taxonomy of fourteen types of values carried by nature, of which most are experientially based. The closing chapter, on persons in natural history, concludes insisting on a need for 'personal backing' to an environmental ethic by those who live in 'storied residence' on their landscapes (Rolston 1987).

Minteer complains that I do not address conflicts between environmental protection and moral commitments to humans 'in any significant sense' (p. 342). Needless to say, having been taken to task by Attfield and Brennan for arguing that we ought sometimes to save nature rather than feed people, I can only conclude that Minteer has not adequately read my other work.

I do not find it 'curious' to speak of 'a world beyond the human mind', as Minteer laments (p. 337). Every time he seeks to couple up both social and natural values, Minteer concedes that there is a world out there, outside the human mind, of which we can take some account. I would find it curious to know how Minteer makes his way around if he does not believe in such a world, and does not know something reliable about it (where the frees are and the tigers aren't).

Minteer, I am sure, knows where the trees and the tigers are; his problem is that he does not know how to value them except insofar as he, or his culture, or subculture, chooses to take up some attitude toward them. Other cultures may take up other attitudes. The Nepalis might choose to burn the Chitwan sal forest 


\section{HOLMES ROLSTON, III}

for fuel, shoot the tigers, and graze their cattle and buffalo in the former park. If that is their cultural occupation, well and good. Or, if within our American culture, 'everyday citizens' did see 'the great forests of the Northwest as a resource to be taken possession of, exploited. (a characteristic view, I still maintain, of lumbermen who have cut the redwoods and Douglas-firs over many decades) (Minteer, p. 338), nobody thinking otherwise could complain, neither Minteer nor environmentalists who think that these old growth forests might contain values being overlooked. Nobody knows whether there is any intrinsic value out there worth respecting. There are no 'privileged' views, only 'ideologies', Minteer's included (cf. Minteer, p. 336, p. 343).

Minteer will reply that he wants to take account of a pluralism of values in human experiences. He wants a democratic debate among contesting parties (p. 347). I think he is left in a muddle. Talk about a debate that is a 'non-starter'! (p. 343). In this one, there are no grounds (aka 'foundations') for argument: the outcome will be only be the resultant in a power struggle, which may be disguised as 'pragmatic'. One thing of which Minteer cannot take adequate account is what was there before these contingent human valuers, sometimes exploiters, came around, such as those rhinoceros and tigers, or the old growth forests, and what might still be there, even if only in relics, should humans choose to preserve it. With that (against Brennan) I confess to find in my nature 'Puritanism', not moral virtue, not 'purity', but value worthy of respect in wild things, sufficient at times to take priority over human needs. I run the risk of being misanthropic; that is better than to risk being an arrogant humanist. And I welcome continuing debate about how, in these dilemmas, to be most humane.

\section{NOTE}

${ }^{1}$ The Vitousek claim about humans capturing $40 \%$ of the terrestrial primary product is not essential to my argument, as Attfield recognises. Sagoff s easy dismissal that all of North America was co-opted already in 1492, since the Indians roamed over all of it, is no serious response. Modern agriculture, range management, timbering, irrigation, road-building, and so on have dramatically co-opted the American landscape, easily $40 \%$ of it, as native Americans never did. Herman Daly, in his response to Sagoff judges the Vitousek calculation 'a reasonable estimate to put some quantitative dimension on the scale of the human economy relative to the total ecosystem' (1995: 623).

\section{REFERENCES}

Cunningham, Carol, and Berger, Joel 1997. The Horn of Darkness: Rhinos on the Edge. New York: Oxford University Press.

Daly, Herman 1995. 'Response to Mark Sagoff's "Carrying Capacity and Ecological Economics".' BioScience 45:621-624. 
SAVING NATURE . .

Nepal, Sanjay Kumar and Weber, Karl E. 1993. Struggle for Existence: Park-People Conflict In the Royal Chitwan National Park, Nepal. Bangkok, Thailand: Asian Institute of Technology.

Rolston, Holmes, III 1987. Environmental Ethics: Duties to and Values in the Natural World. Philadelphia: Temple University Press.

Rolston, Holmes, III 1997. 'Nature for Real: Is Nature a Social Construct?' Pages 38-64 in T.D.J. Chappell, ed., The Philosophy of the Environment. Edinburgh: University of Edinburgh Press.

Rolston, Holmes, III 1996. 'Feeding People versus Saving Nature?' Pages 248-267 in William Aiken and Hugh LaFollette, eds., World Hunger and Morality; 2nd edition, Upper Saddle River, NJ: Prentice-Hall. Reprinted in Roger S. Gottlieb, ed., The Ecological Community (London: Routledge, 1967), pages 208-225. Reprinted in Hugh LaFollette, ed., Ethics in Practice: An Anthology (Oxford: Blackwell Publishers, Ltd. 1997), pages 619-630. Also reprinted in Donald VanDeVeer and Christine Pierce, eds., The Environmental Ethics and Policy Book: Philosophy Ecology, Economics, 2nd ed. (Belmont, CA: Wadsworth Publishing Co., 1998), pages 409420. Translated into German as 'Menschen Emähren oder Natur Erhalten?' in Conceptus: Zeitschrifi für philosophie 29(nr. 74, 1996): 1-25, with reply, 'Natur Erhalten oder Menschen Emähren?' ('Saving Nature or Feeding People?') by Robin Attfield (Philosophy, University of Wales), Conceptus 29: 27-45.

Shrestha, Nabina 1997. Protected Species of Nepal. Kathmandu: IUCN Nepal.

World Health Organization, Commission on Health and Environment 1992. Our Planet, Our Health. Geneva: World Health Organization. 